\section{PERFIL DE PORTADORES DE HEPATITE B EM UM SERVIÇO DE REFERÊNCIA: ESTUDO RETROSPECTIVO}

\author{
Profile of hepatitis $B$ patients in a reference service: \\ retrospective study
}
Perfil de portadores de hepatitis $B$ de un servicio de referencia: estudio retrospectivo

\section{RESUMO}

Objetivo: Conhecer o perfil dos pacientes portadores de hepatite B atendidos no Núcleo de Estudos do Fígado (NEF) da Universidade Federal do Rio Grande do Norte (UFRN). Método: Estudo descritivo, retrospectivo, que analisou 433 prontuários, tendo confirmação sorológica para 279 destes. Foram coletadas variáveis sociodemográficas, de comportamento sexual, histórico de transfusão, procedimento cirúrgico/odontológico anterior e passado de hepatite, sendo utilizada a análise descritiva dos dados. Resultados: Todos (100\%) apresentaram sorologia positiva para hepatite B. Das variáveis, as mais determinantes foram sexo masculino (77,8\%; $\mathrm{n}=217$ ), idade (entre 46-60 anos), estado civil (casados: $56,63 \%$; $\mathrm{n}=158)$, e 48,39\% (135) eram procedentes de bancos de sangue. Seis em cada dez $(38,7 \%$; $\mathrm{n}=108$ ) haviam realizado procedimentos odontológicos ou cirúrgicos, dois em cada dez $(20 \% ; n=56)$ apresentavam promiscuidade sexual e apenas um em cada dez $(10 \% ; n=28)$ relataram passado de hepatite viral. Conclusão: O perfil encontrado aponta para indivíduos do sexo masculino, heterossexual, casado, em idade produtiva, doador de sangue, cuja fonte de infecção não pôde ser precisamente estabelecida.

Descritores: Hepatite; Hepatite B; Marcadores Biológicos.

\section{ABSTRACT}

Objective: To know the profile of patients with hepatitis B treated at the Liver Research Center (NEF) of the Federal University of Rio Grande do Norte (UFRN). Methods: Descriptive, retrospective study that analyzed 433 medical records with serological confirmation for 279 of them. Authors collected information on sociodemographics, sexual behavior, history of transfusion, surgical/dental procedures previous and after history of hepatitis, and performed descriptive analysis of data. Results: All the participants (100\%) tested positive for hepatitis $B$. The most determinant variables were male gender $(77.8 \% ; n=217)$, age (46-60 years), marital status (married: $56.63 \% ; n=158$ ), and $48.39 \%(135)$ of the patients came from blood banks. Six in ten patients $(38.7 \% ; n=108)$ had undergone dental or surgical procedures, two in ten $(20 \% ; n=56)$ presented sexual promiscuity and only one in ten $(10 \% ; n=28)$ reported previous viral hepatitis. Conclusion: The profile identified included male, heterosexual, married individuals at working age who were blood donors and whose source of infection could not be precisely identified.

Descriptors: Hepatitis; Hepatitis B; Biological Markers.

\section{RESUMEN}

Objetivo: Conocer el perfil de los pacientes portadores de hepatitis B asistidos en el Núcleo de Estudios del Hígado (NEH) de la Universidad Federal de Rio Grande del Norte (UFRN). Métodos: Estudio descriptivo y retrospectivo, que analizó 433 historiales clínicos con confirmación serológica de 279 de ellos. Fueron recogidas variables sociodemográficas, de conducta sexual, historial de transfusión, procedimiento quirúrgico/odontológico anterior e historia de hepatitis a través de un análisis descriptivo de los datos. Resultados: Todos
Artigo Original

\author{
Erotides Maria Garcia Justino ${ }^{(1)}$ \\ Sílvia Silveira Soriano Bacelar ${ }^{(2)}$ \\ Silvana Dantas de Araújo ${ }^{(3)}$ \\ Ruy Medeiros de Oliveira ${ }^{(4)}$ \\ Edileuza Bezerra de Almeida ${ }^{(1)}$ \\ Gilmar Amorim de Sousa ${ }^{(2)}$ \\ Iris do Céu Clara Costa ${ }^{(2)}$
}

1) Secretaria Estadual de Saúde do Rio
Grande do Norte - Natal (RN) - Brasil

2) Universidade Federal do Rio Grande do Norte (UFRN) - Natal (RN) - Brasil

3) Secretaria Municipal de Saúde de Natal Natal (RN) - Brasil

4)Maternidade Escola Januário Cicco, Universidade Federal do Rio Grande do Norte (UFRN) - Natal (RN) - Brasil
Recebido em: 20/02/2013 Revisado em: 09/05/2013 Aceito em: 24/01/2014 
(100\%) presentaron serología positiva para la hepatitis B. De las variables, las más determinantes fueron el sexo masculino (77,8\%; $n=217)$, edad (46-60 años), estado civil (casados: $56,63 \%$; $n=158)$, y el 48,39\% (135) eran procedentes de bancos de sangre. Seis de cada diez $(38,7 \% ; n=108)$ habian realizado procedimientos odontológicos o quirúrgicos, dos de cada diez $(20 \% ; n=56)$ presentaron promiscuidad sexual y solamente uno de cada diez $(10 \% ; n=28)$ relataron haber tenido hepatitis viral. Conclusión: El perfil identificado sugiere individuos del sexo masculino, heterosexual, casado, de edad productiva y donante de sangre cuya fuente de infección no pudo ser exactamente establecida.

Descriptores: Hepatitis; Hepatitis B; Marcadores Biológicos.

\section{INTRODUÇÃO}

As hepatites virais são doenças provocadas por diferentes agentes etiológicos, com tropismo pelo fígado, que apresentam características epidemiológicas, clínicas e laboratoriais distintas. Segundo estimativas disponíveis na literatura pertinente, bilhões de pessoas já tiveram contato com vírus das hepatites e milhões são portadores crônicos. A vigilância epidemiológica das hepatites virais no Brasil é baseada na notificação compulsória dos casos suspeitos. A partir disso, há um prazo de 180 dias para investigação e encerramento oportuno do caso. Assim, os dados das hepatites virais são organizados de acordo com os casos confirmados e por ano de notificação, momento no qual o caso tornou-se conhecido pela vigilância. Entre os anos de 2005 e 2010, foram notificados e confirmados, no Rio Grande do Norte, 2.167 casos de hepatite A, 210 casos de hepatite B e 306 casos de hepatite $\mathrm{C}^{(1,2)}$.

Por sua vez, a hepatite B crônica é causada pelo vírus da hepatite B (VHB), cuja principal via de transmissão é a sexual, seguida da vertical (de mãe para filho), contato com sangue, vias parenteral e percutânea, além de fluidos corporais ${ }^{(1)}$. Essa doença figura como um importante problema de saúde pública em todo o mundo e a estimativa é que existam cerca de 2 mil milhões de infectados pelo VHB e cerca de 400 milhões de pessoas com hepatite B crônica em todo o mundo. No Brasil, de modo geral, $1 \%$ a $3 \%$ da população são infectados cronicamente pelo vírus da hepatite $\mathrm{B}^{(3)}$.

A hepatite B é uma doença bem conhecida do ponto de vista clínico, laboratorial e epidemiológico. Trata-se da mais frequente forma de hepatite infecciosa, sendo a nona causa de mortalidade no mundo. Ao contrário do vírus da hepatite A (HAV), o HBV permanece no sangue durante os últimos estágios de um período de incubação prolongado (4 a 26 semanas) e durante episódios agudos de hepatite aguda e crônica. Também está presente em todos os líquidos corporais fisiológicos e patológicos. O sangue e os líquidos corporais são os veículos primários de transmissão, e o vírus pode se propagar por contato com secreções corporais, como sêmen, saliva, suor, lágrimas, leite materno e efusões patológicas. Embora a infecção possa ocorrer em qualquer indivíduo, alguns grupos são particularmente expostos ao VHB, em função de comportamentos de risco ou da atividade profissional, em cuja categoria se enquadra os profissionais da área da saúde, nos quais o risco de contrair a doença é de duas a dez vezes maior que da população geral $^{(1,3)}$.

Estima-se que existam aproximadamente 350 milhões de portadores crônicos do HBV distribuídos em diversas regiões do mundo, além dos que morrem anualmente em consequência de doença hepática crônica que representa cerca de um milhão de pessoas, tendo a Ásia, Pacífico Sul e África a maior incidência e prevalência em todo o mundo. Em áreas sabidamente endêmicas de infecção pelo VHB, como a Ásia, prevalece a transmissão vertical (mãefilho). Em outras áreas, a transmissão do VHB é geralmente horizontal (per cutânea, sexual). No Brasil, o problema estaria localizado na Região Amazônica, em especial, na Amazônia Ocidental. A Região Amazônica tem incidência comparável às maiores do mundo, pois de $5 \%$ a $15 \%$ de seus habitantes são portadores crônicos do $\mathrm{VHB}^{(3-5)}$.

De 1999 a 2011, foram notificados 11.017 casos de hepatite B na Região Nordeste, o que corresponde a 9,2\% do total de casos no Brasil. Em 2010, foram notificados 1.304 casos, $9,9 \%$ do total no Brasil para esse ano, a maioria nos estados da Bahia (30,4\%) e do Maranhão (14,3\%). Para o ano de 2010, observa-se uma taxa de detecção de casos de hepatite B por 100.000 habitantes de 2,5 abaixo da taxa de detecção nacional (6,9\%). Além disso, as maiores taxas de detecção se observam em Sergipe $(4,6 \%)$, seguido por Alagoas (3,6\%), Paraíba (3,4\%), Maranhão e Bahia (2,8\%). Dentre as capitais da região, em 2010, observaram-se as maiores taxas de detecção por 100.000 habitantes em João Pessoa-PB $(10,9 \%)$ e São Luís-MA $(7,7 \%)^{(6)}$.

Em 2010, excluídos os casos ignorados/em branco, a provável fonte/mecanismo de infecção mais frequente é o contato sexual $(60,4 \%)$, seguido de contato domiciliar $(5,6 \%)$, transfusão $(4,0 \%)$, transmissão vertical $(1,9 \%)$, uso de drogas $(1,9 \%)$, hemodiálise $(1,4 \%)$, acidente de trabalho $(1,4 \%)$ e outros $(23,3 \%)$. No período de 2000 a 2011, na Região Nordeste, ocorreram 1.257 óbitos por hepatite B, sendo 770 como causa básica e 487 como causa associada, a maioria em Pernambuco (447 óbitos; 22,5\%) e na Bahia (442 óbitos; $22,3 \%)^{(6)}$. 
No estado do Rio Grande do Norte, entre 2005 e o $1^{\circ}$ semestre de 2010 , foram notificados e confirmados no SINAN (Sistema de Informação de Agravos de Notificação - Ministério da Saúde - MS - Brasil) 218 casos de hepatite B, distribuídos em $20 \%$ dos municípios. Entre os anos de 2007 e 2008, implantou-se o Programa Estadual das Hepatites Virais, com investimentos em capacitações de vigilância epidemiológica, a fim de melhorar a qualidade da notificação. O indicador "proporção de casos de hepatite B confirmados por sorologia" é usado pelo Pacto pela Saúde para monitorar os casos no SINAN quanto à realização do exame sorológico específico para a confirmação de caso por critério laboratorial. No Rio Grande do Norte, entre os anos de 2005 e 2010, a média desse indicador foi de $86 \%{ }^{(2)}$.

Quanto à prevalência desse agravo na população, temse a seguinte classificação: elevada quando maior ou igual a $8 \%$; intermediária, entre $2 \%$ e $7 \%$; e baixa quando atinge o patamar menor que $2 \%$. Sobre as complicações advindas, de $15 \%$ a $40 \%$ dos portadores do vírus irão desenvolver complicações graves ao longo da vida e anualmente o VHB tem sido responsável por 0,5 a 1,2 milhões de mortes por cirrose e carcinoma hepáticos ${ }^{(3)}$, embora a longo prazo o tratamento possa prevenir e retardar o desenvolvimento dessas complicações. Sendo assim, é fundamental definir em qual fase da história natural o doente se encontra. Essa definição é feita baseada na presença ou ausência de $\mathrm{AgHBe}$, replicação vírica (DNA VHB), valor de ALT e histologia hepática. Tal avaliação possibilita traçar o perfil de cada doente, de maneira a eleger a melhor estratégia de tratamento ${ }^{(3,6)}$.

Dados da Organização Mundial da Saúde (OMS) revelam que uma em cada 30 pessoas no Brasil pode estar infectada pelos vírus causadores das hepatites B e C. Quando analisada a população mundial, as estatísticas são ainda piores: uma em cada 12 pessoas é portadora de um desses vírus. A hepatite representa a $10^{\mathrm{a}}$ causa de morte no mundo. $\mathrm{O}$ vírus $\mathrm{B}$ é altamente contagioso na relação sexual - 100 vezes mais do que o HIV. Só no Brasil, o Ministério da Saúde estima que mais de dois milhões de pessoas já foram contaminadas ${ }^{(7) .}$

Desde 8 de dezembro de 2003, as hepatites virais passaram a ser Doença de Notificação Compulsória (DNC), através da Portaria n $^{\circ} 2325$ do Ministério da Saúde, para todo o território nacional. Foram descritos dados dos bancos de sangue da América Latina, em que os portadores do vírus da hepatite $\mathrm{B}$ (VHB) excedem seis milhões, estando o Brasil e outros países da América do Sul, como Colômbia, Venezuela e Peru, dentre aqueles que apresentam territórios de elevada endemicidade. A variação da frequência da hepatite pelo VHB no Brasil é de $0,5 \%$ a $1,1 \%$ na região Sul, enquanto na Região Centro-Oeste e Nordeste varia de $1,5 \%$ a 3,0\%, alcançando $15 \%$ na Região Amazônica, o que mostra alta endemicidade ${ }^{(6)}$.
Apesar de a soroprevalência da hepatite B estar presente em diversas regiões do país, ainda existem lacunas no conhecimento da morbimortalidade dessa doença. Observa-se que, mesmo com anamneses extremamente cuidadosas, não se identificam fatores de risco conhecidos em percentuais consideráveis de indivíduos com quadros crônicos, chegando esse desconhecimento a valores aproximadamente iguais a $30 \%$ para essa doença. Possivelmente a falta de conhecimento científico por parte dos profissionais de saúde sobre o assunto e a fragilidade do sistema de vigilância epidemiológica nos diversos níveis contribuem para a baixa implementação das medidas de controle da doença ${ }^{(8,9)}$.

Condições como heterogeneidade socioeconômica, má distribuição dos serviços de saúde, incorporação desigual de tecnologia avançada para diagnóstico e tratamento de enfermidades são essenciais na avaliação do processo endemoepidêmico das hepatites virais. Quando se compara estados e municípios brasileiros entre si, o número de pacientes infectados é muitas vezes desconhecido ou não registrado adequadamente, considerando que a confirmação do diagnóstico das hepatites requer técnicas laboratoriais complexas de biologia molecular, o que onera e dificulta a implantação de serviços dessa natureza ${ }^{(9)}$.

Segundo o Ministério da Saúde, a execução da busca ativa permite a identificação de novos casos, em especial, entre os comunicantes. Os assintomáticos são indivíduos expostos a uma fonte de infecção bem documentada, seja na hemodiálise, em acidente ocupacional com exposição percutânea ou de mucosas, por transfusão de sangue ou hemoderivados, procedimentos cirúrgico-odontológicos, colocação de piercings/tatuagem com materiais não esterilizados, ou por uso de drogas com compartilhamentos de instrumentos. Comunicantes de casos confirmados de hepatite, independentemente da forma clínica e evolutiva do caso índice, e pessoas com alteração de aminotransferase no soro igual ou três vezes maior que o valor máximo normal dessas enzimas, segundo o método utilizado, são a constatação de uma nova busca ativa ${ }^{(10)}$.

Os marcadores que permitem diagnosticar a hepatite $\mathrm{B}$ surgem no sangue em tempos diferentes. Normalmente, o primeiro a detectar-se é o antígeno HbsAg, o qual persiste de um a três meses e demonstra a presença do vírus no organismo. O HBsAg, ou AgHBs, é o primeiro marcador sorológico que aparece, coincidindo com os sintomas quando atinge concentração máxima, embora possa se apresentar positivo antes mesmo dos sintomas ${ }^{(2)}$. Um pouco mais tarde (em alguns casos, simultaneamente) surge o antígeno $\mathrm{HBeAg}$, que significa a multiplicação do agente infeccioso. É nessa fase que o perigo de contágio é mais elevado. Só depois surgem os anticorpos e o primeiro a aparecer, na maioria das vezes, é o anti-HBc. Em seguida, se 
as defesas imunitárias do organismo estiverem funcionando corretamente, surge o anti-HBe, como resposta ao antígeno $\mathrm{HBeAg}$. Isso significa que houve uma soroconversão, na qual a multiplicação do vírus diminuiu e, se nada alterar o curso normal, o antígeno HBs desaparece, surgindo o anticorpo anti-HBs, que permanece no organismo para o resto da vida, conferindo imunidade. A presença do antígeno $\mathrm{HBeAg}$ além de oito semanas indica que a hepatite está caminhando para uma fase crônica e a permanência do antígeno HBsAg por mais de seis meses confirma a passagem para cronicidade. O tratamento da hepatite B é feito apenas com sintomáticos, repouso relativo e evitandose a ingestão de álcool ${ }^{(11,12)}$.

Considerando-se a magnitude do problema e levando em conta a existência de uma grande deficiência tanto no conhecimento dos profissionais em relação à patologia quanto na política de prevenção hoje instituída pelo Ministério da Saúde, reforça-se que a não apropriação do conhecimento dificulta a implementação de políticas públicas de controle e tratamento relacionado às hepatites virais $^{(12,13)}$.

Ressalta-se ainda a importância da abordagem pessoal e familiar, considerando que os sentimentos e as mudanças no cotidiano como decorrentes do diagnóstico de hepatite revelam que saber-se portador de uma doença infecciosa e transmissível traz preocupações e incertezas, especialmente quando se trata de doença silenciosa, de curso lento e prognóstico variável. A falta de conhecimento que a população em geral tem sobre a doença, mais precisamente sobre modo de transmissão, evolução, prognóstico, efeitos colaterais do tratamento, entre outros aspectos, tornam os indivíduos frágeis e impotentes para o enfrentamento dela ${ }^{(14,15)}$. Esses aspectos psicossociais reiteram a relevância do presente trabalho. Conhecendose o perfil dos usuários, abrem-se maiores possibilidades do devido acompanhamento. A importância e relevância de se ter esse perfil do ponto de vista da promoção da saúde são as possibilidades que se criam de seguimento e acompanhamento dos pacientes positivados na primeira sorologia, com monitoramento do seu retorno para confirmação do diagnóstico por exames complementares, prevenindo-se que sejam elementos contaminantes de outras pessoas e que mantenham sua doença sob controle.

Assim, levando-se em conta a importância do contexto da hepatite B no mundo, no Brasil, na região Nordeste e no estado do Rio Grande do Norte, bem como as formas de contaminação e distribuição dessa doença, o presente estudo tem por objetivo conhecer o perfil dos pacientes portadores de hepatite B atendidos no Núcleo de Estudos do Fígado (NEF) do Hospital Universitário Onofre Lopes (HUOL) da Universidade Federal do Rio Grande do Norte (UFRN).

\section{MÉTODOS}

Estudo descritivo, retrospectivo, realizado por ocasião do Curso de Especialização em Epidemiologia, surgiu da necessidade dos autores que trabalham com a vigilância das hepatites de conhecer o perfil dos usuários, para compreender melhor esse fluxo desde a entrada do paciente na rede (Unidades Básicas de Saúde, Hemocentro, hospitais etc.) até seu encaminhamento ao serviço de referência estudado (NEF-HUOL-UFRN) da cidade de Natal RN. Natal é a capital do estado do Rio Grande do Norte, situado no Nordeste do Brasil. Segundo dados do Instituto Brasileiro de Geografia e Estatística (IBGE), sua população em 2009 era de 806.203 habitantes, com $46,87 \%$ para o sexo masculino e $53,08 \%$ do sexo feminino, apresentando uma densidade populacional de $4.734,07 \mathrm{hab} / \mathrm{km}^{2}$. O Índice de Desenvolvimento Humano (IDH) geral do município é de 0,788 (médio) ${ }^{(16)}$.

A coleta de dados ocorreu em 2011, através da análise de prontuários dos pacientes atendidos no Núcleo de Estudos do Fígado (NEF) do Hospital Universitário Onofre Lopes (HUOL) da Universidade Federal do Rio Grande do Norte (UFRN), em Natal-RN, na série histórica 2005-2009. A eleição dessa série histórica deveu-se ao fato de que, a partir de 2005, o NEF passou a ser referencia para todo o estado (antes disso, atendia apenas pacientes internados no HUOL), e o limite de 2009, por ser o ano cujos prontuários já estavam arquivados e as informações, consolidadas e disponíveis.

A população estudada consistiu de portadores de hepatite B referenciados ao NEF, classificados segundo os marcadores de triagem da infecção adotados pelo Ministério da Saúde ${ }^{(10)}$.

O HUOL, por sua vez, foi fundado em 5 de fevereiro de 1955, tendo sido integrado ao Sistema Único de Saúde (SUS), como referência terciária a partir da Lei Orgânica da Saúde $\mathrm{n}^{\circ} 8.080$ em 1988. O NEF é um serviço de referência do SUS no estado, implantado no HUOL em 1995 para acompanhamento ambulatorial de pacientes com doenças hepáticas crônicas, atendidos no Hospital Universitário Onofre Lopes em Natal, cujo serviço foi expandido em 2005 para os outros municípios ${ }^{(17)}$.

Quanto ao atendimento, no período estudado correspondente à série histórica 2005-2009, o NEF acolheu 2.603 pacientes. Analisaram-se 433 prontuários de pacientes, que eram casos suspeitos de hepatite $B$, dos quais 279 apresentaram confirmação, constituindo-se a amostra selecionada do presente estudo.

Os critérios de inclusão foram os mesmos usados pelo Ministério da Saúde definidos no manual $A B C D E$ do Diagnóstico para as Hepatites Virais, a partir do qual se 
detectou a presença dos seguintes marcadores sorológicos: antígeno de superfície contra o vírus da hepatite $\mathrm{B}$ (HBsAg) e/ou anticorpo IgM contra o vírus B (Anti-HBc IgM) e/ ou anticorpo IgG contra o vírus B (Anti-HBc IgG) e/ou $\mathrm{HBeAg}$ e/ou Anti-HBe ${ }^{(10)}$. Os critérios de exclusão foram: o usuário não ter sido referenciado ao NEF e a incompletude do prontuário no que se refere aos marcadores sorológicos da hepatite B.

$\mathrm{O}$ instrumento de coleta foi representado pelos prontuários dos pacientes atendidos no NEF. Inicialmente, por meio da busca direta no livro de registro de atendimentos, realizou-se um levantamento preliminar de todos os prontuários de possíveis casos de hepatite $\mathrm{B}$, descartando aqueles que não se enquadravam nos critérios de inclusão. Além dos 279 que tiveram seus prontuários selecionados e deram seguimento ao tratamento, 154 pacientes, apesar de positivos na triagem sorológica inicial, não retornaram ao NEF para mostrar os exames solicitados na primeira consulta. Os prontuários foram arquivados no próprio serviço, no formato impresso, em pastas organizadas por ano de atendimento, e realizou-se a busca de forma manual. Portanto, esses casos inconclusivos foram considerados possíveis portadores da doença, embora estivessem sem confirmação da suspeita, representando um percentual de abandono ao tratamento e impossibilidade de seguimento de $35,56 \%$.

A presente pesquisa considerou variáveis independentes, como sexo, idade, estado civil, procedência (serviço que referenciou), histórico de transfusão, utilização de droga parenteral, realização de procedimento cirúrgico, de procedimento odontológico anterior, orientação sexual, número de parceiros, contato íntimo com caso de hepatite, passado de hepatite viral e presença de marcadores sorológicos para a hepatite B (HBsAg, Anti-HBc IgM, Anti-HBc IgG, HBeAg, Anti-HBs, HBV-DNA, Anti-Hbe). $A$ variável dependente é o agravo hepatite $B$.

Importante registrar que, conforme recomenda a Resolução no 196/96, do Conselho Nacional de Saúde do Ministério da Saúde, vigente no período da coleta, revogada recentemente pela Resolução $n^{\circ}$ 466/2012, e que regulamenta a pesquisa em seres humanos no país. Embora o estudo tenha utilizado dados secundários, manteve os padrões éticos em pesquisas dessa natureza, resguardando o anonimato e respeitando a confidencialidade dos sujeitos. Portanto, a pesquisa teve a anuência da direção do NEFHUOL, da qual se solicitou autorização e recebeu aprovação pelo Comitê de Ética da UFRN, tendo recebido parecer $n^{\circ}$ $173 / 2011$.

Os dados foram analisados pela estatística descritiva.

\section{RESULTADOS}

A amostra deste estudo englobou 279 prontuários, porém, excluíram-se 154 , por não retornarem ao serviço para a realização dos testes sorológicos e exames complementares necessários à conclusão do caso e devido acompanhamento clínico periódico, totalizando um $n=125$.

Os dados serão apresentados e discutidos a partir das ilustrações na Tabela I.

Tabela I - Perfil dos casos de hepatite B atendidos no NEFUFRN na série histórica 2005-2009. Natal-RN, 2011.

\begin{tabular}{lcc}
\hline Variável & n & \% \\
\hline Sexo & 217 & 77,8 \\
Masculino & 62 & 22,2 \\
Feminino & & \\
Faixa etária & 63 & 22,6 \\
Até 35 anos & 62 & 22,2 \\
36 a 45 anos & 97 & 34,8 \\
46 a 60 anos & 57 & 20,4 \\
61 anos e + & & \\
Estado civil & 158 & 56,6 \\
Casado & 87 & 31,2 \\
Solteiro & 21 & 7,5 \\
Viúvo & 10 & 3,6 \\
Divorciado & 3 & 1,1 \\
Outros & & \\
Orientação sexual & 225 & 80,6 \\
Heterossexual & 2 & 0,75 \\
Homossexual & 2 & 0,75 \\
Bissexual & 50 & 17,9 \\
Sem informação &
\end{tabular}

Fonte: Prontuários do NEF, Natal-RN, 2011

Dentre os casos estudados, observou-se uma prevalência maior de casos de hepatite B no sexo masculino.

Com relação à distribuição segundo faixa etária, houve uma predominância no grupo de 46 a 60 anos para o sexo masculino $(77,8 \% ; n=217)$ e de 36 a 45 anos para o sexo feminino $(22,2 \% ; n=62)$.

A distribuição segundo estado civil revelou predominância dos casados $(56,63 \% ; n=158)$, seguidos de 87 solteiros (31,18\%), 21 viúvos (7,53\%), 10 divorciados $(3,58 \%)$ e $3(1,08 \%)$ sem informação.

Com relação à orientação sexual, observa-se que $80,6 \%$ $(n=225)$ são heterossexuais e uma minoria, $1,5 \%(n=4)$, é homossexual ou bissexual. A proporção sem informação foi de $17,9 \%(n=50)$. 
Quanto aos fatores de risco, encontrou-se: 67,4\% $(n=188)$ dos casos se submeteram a procedimentos odontológicos, $55,2 \%(\mathrm{n}=154)$ realizaram procedimento cirúrgico, 20,0\% $(\mathrm{n}=56)$ relataram promiscuidade sexual, $14,7 \% \quad(n=41)$ haviam realizado transfusão de sangue, $10,0 \%(\mathrm{n}=28)$ têm história pregressa de hepatite viral e $7,1 \%(n=20)$ tiveram contato íntimo com caso de hepatite não especificada.

Na Figura 1, verifica-se a instituição de procedência do usuário, ou seja, aquela que encaminhou o paciente para o NEF.

Quanto à procedência, 48,39\% $(n=135)$ dos casos foram encaminhados dos dois bancos de sangue situados em Natal (Hemonorte e Hemovida, sendo o primeiro público e o segundo privado). Após resultado positivo na triagem sorológica para doação, $17,92 \%(n=50)$ eram de usuários atendidos no HUOL, 11,83\% (n=33) eram provenientes da SMS Natal e 13,26\% $(n=37)$ eram de outras cidades do estado, além de outras instituições hospitalares e ambulatoriais, em menores proporções, 8,6\% $(n=24)$.

A Figura 2 ilustra os encaminhamentos de casos positivos de hepatite $\mathrm{B}$ dos diversos municípios do Rio Grande do Norte para o NEF-UFRN, sendo o município de Natal o que encaminhou o maior número de casos. Outros municípios, como Parnamirim, Currais Novos, Pau dos Ferros, Ceará Mirim, Pureza, São Gonçalo do Amarante e Extremoz referenciaram 17 casos, correspondendo a 6,09\% do total de 279 casos.

A Figura 2 mostra também que $130 \quad(77,84 \%)$ municípios, dos 167 que compõem o estado, não encaminharam pacientes com suspeita de hepatite B ao NEF.

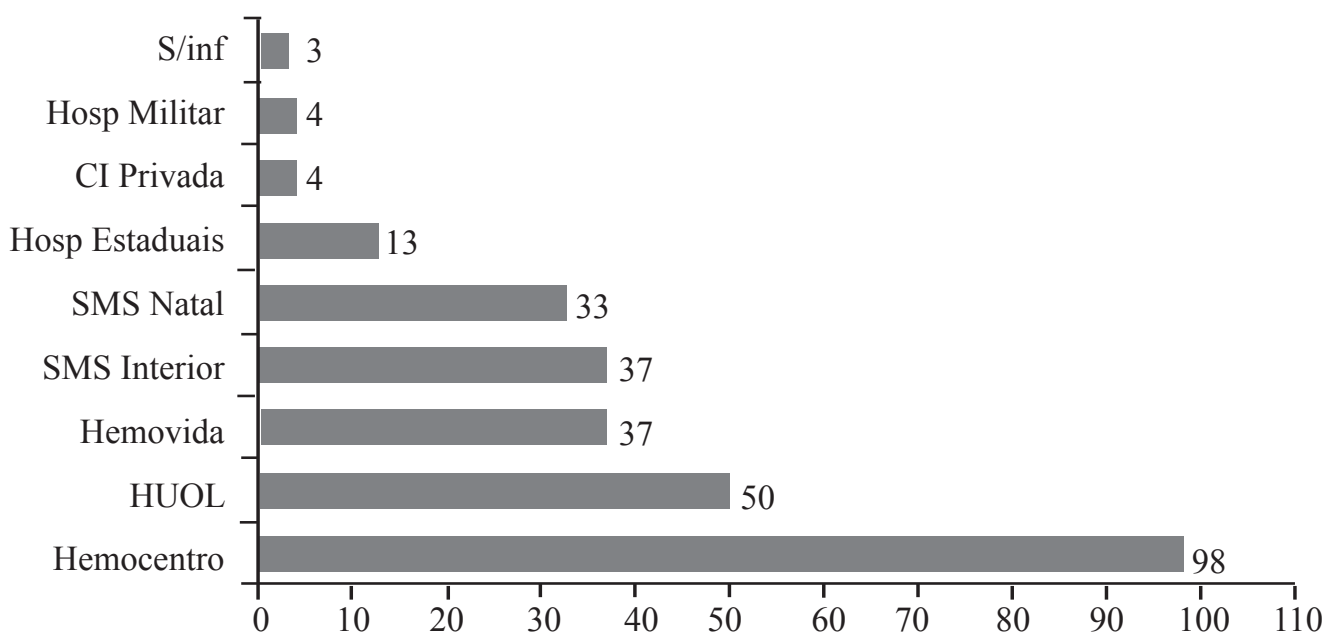

Figura 1 - Procedência dos casos de hepatite B atendidos no NEF/UFRN na série histórica 2005-2009. Natal-RN, 2011.

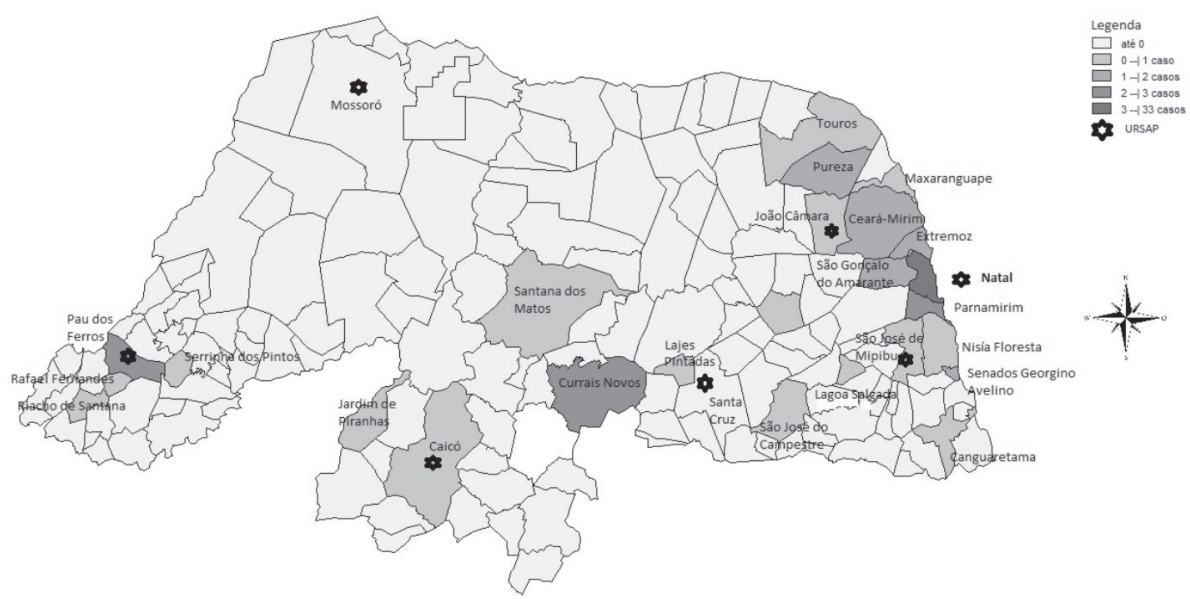

Figura 2 - Municípios do Rio Grande do Norte que encaminharam casos positivos de hepatite B para o NEF-UFRN na série histórica 2005-2009. Natal-RN, 2011. 


\section{DISCUSSÃO}

Conforme a literatura pesquisada ${ }^{(1,3,5,7)}$, a prevalência e a incidência do VHB se configuram como um relevante problema de saúde pública para todos os países do mundo, mesmo considerando as características demográficas e sócio-econômicas das distintas regiões.

Os avanços das medidas de controle, como a vacinação de grupos específicos e as campanhas educativas contra a AIDS e hepatites virais, vêm contribuindo para uma tendência de redução em indivíduos portadores, mas ainda estima-se um elevado número de casos em todo o mundo e, a despeito de tudo isso, existe uma dificuldade relacionada à notificação de casos, caracterizando uma subnotificação, inclusive em serviços considerados de qualidade ${ }^{(7,13)}$.

Nos resultados demonstrados na presente pesquisa, observa-se que o perfil epidemiológico não diverge dos dados descritos na literatura mundial e nacional ${ }^{(5,6,10,11,12,14)}$.

Em um estudo com 673 candidatos que procuraram o Centro de Hematologia e Hemoterapia do Acre, foi observada, na pré-triagem sorológica para hepatite $\mathrm{B}$ (anti-HBc total), uma associação entre as variáveis sexo, faixa etária e escolaridade, tendo sido verificada maior reatividade ao anti-HBc total em $54,8 \%$ dos homens com faixa etária mais avançada e menor grau de escolaridade ${ }^{(8)}$.

A maior prevalência de marcadores sorológicos nos sujeitos amostrais do sexo masculino indica que estes podem estar mais expostos ao vírus da hepatite $\mathrm{B}$, provavelmente devido ao comportamento sexual, ou simplesmente representa um viés amostral, em virtude de a maioria ser oriunda de hemocentros após teste positivo na triagem sorológica para doação sanguínea, o que pode explicar a predominância do sexo masculino, visto que os doadores são constituídos por mais homens do que mulheres. Essa situação foi evidenciada por estudos com marcadores séricos das hepatites $\mathrm{B}$ e $\mathrm{C}$ em doadores de sangue em outras pesquisas, nas quais a soropositividade da hepatite $B$ foi três vezes mais elevada em doadores do sexo masculino ${ }^{(18,19,20)}$. Outros estudos $^{(7,11,12)}$ também demonstraram uma incidência maior da hepatite B no sexo masculino, o que confirma achados do presente trabalho.

No presente estudo, a faixa etária predominante para hepatite B foi de 46 a 60 anos para o sexo masculino e de 36 a 45 anos para o sexo feminino. Nesse sentido, afirma$\mathrm{se}^{(7,12)}$ que existe uma maior predominância de casos na população economicamente ativa, visto que o vírus acomete preferencialmente indivíduos na faixa etária de 20 a 40 anos, provavelmente devido à transmissão sexual e transfusional, cujos achados divergem do presente estudo. A literatura descreve uma associação do VHB com aumento da idade e início da atividade sexual, pois os mecanismos de transmissão mais importantes envolvem aspectos comportamentais adquiridos ao longo da vida, tais como atividade sexual de risco, uso de drogas ilícitas injetáveis, exposição a sangue e hemoderivados, cuja associação de fatores reflete um efeito cumulativo de riscos comportamentais ${ }^{(11,12)}$. Importante destacar que, no presente estudo, não foram diagnosticados casos em faixa etária inferior a 18 anos, porque o serviço analisado atende apenas a pacientes adultos.

Quanto aos fatores de risco pesquisados na presente pesquisa, a forma de abordagem ao paciente pode levar a um viés amostral, dificultando os achados esperados em relação ao perfil descrito na literatura mundial, como observado, por exemplo, nas variáveis "número de parceiros (promiscuidade)" e "orientação sexual". A abordagem ao paciente no preenchimento de algumas informações, como orientação sexual e número de parceiros, possívelmente ficou prejudicada devido à permissão da presença de acompanhante no ato da entrevista. Para maior fidedignidade das informações clínicas, sugere-se que seja adotada a entrevista individual, evitando-se a presença de terceiros, para que a privacidade do usuário seja assegurada, possibilitando que as respostas relacionadas as variáveis como prática sexual, orientação sexual, número de parceiros e utilização de drogas parenterais, variáveis importantes na determinação do perfil sejam verdadeiras e possam representar de forma real e plena o registro das informações.

Com relação à procedência dos pacientes no serviço analisado, evidenciou-se que 135 pacientes $(48,39 \%)$ foram encaminhados de bancos de sangue após resultado positivo na triagem sorológica. Ressalta-se que o Hemonorte, sendo o serviço público de captação de hemocomponentes no estado, referenciou 98 pacientes ao NEF, o que representa $72,5 \%$ dos casos procedentes de hemocentros. Evidencia-se também uma maior demanda dos pacientes referenciados dos serviços públicos $(84,2 \%)$ em relação aos serviços privados $(14,6 \%)$.

Importante comentar que, no presente estudo, algumas dificuldades foram enfrentadas na coleta de dados devido à falta de informatização do serviço. As variáveis "nível de escolaridade", "condições socioeconômicas" e "situação vacinal" não constavam no elenco de informações do prontuário, apesar de estudos ${ }^{(4,5,9,11)}$ demonstrarem o impacto dessas variáveis quanto à inaptidão clínica laboratorial, além de serem representativas na determinação do perfil sócio demográfico e epidemiológico.

Outro aspecto observado no presente estudo foi que um número significativo de pacientes referenciados $(\mathrm{n}=154)$, possíveis portadores da hepatite $\mathrm{B}$, chegaram ao $\mathrm{NEF}$ em um primeiro momento e não retornaram para a continuidade da investigação. Isso demonstra uma perda no acompanhamento desses casos e uma articulação 
insatisfatória entre os serviços que fazem parte da rede, o que, em um estudo de incidência, poderia mascarar a real situação da hepatite $\mathrm{B}$ no estado, pois esses casos inconclusivos não seriam computados. Considerando que o NEF-UFRN é o centro de referência estadual do Rio Grande do Norte para avaliação de pacientes portadores de hepatopatias, que vem cumprindo sua missão e que tem forte inserção social na rede SUS, sugere-se a implantação de um serviço de busca ativa dos pacientes que não retornam, a fim de que seja feito o monitoramento necessário para confirmação do diagnóstico, acompanhamento e orientação terapêutica. No que se refere à hepatite $\mathrm{B}$, doença silenciosa e grave, isso ampliará sua esfera de atuação, reforçando seu papel, fortalecendo elos na cadeia da promoção da saúde baseada na alimentação dos sistemas oficiais de dados, com redução da subnotificação e incompletude de informações que certamente trarão reflexos de mudanças na qualidade de vida e no perfil de portadores.

É importante ressaltar que a maioria das pessoas desconhece sua condição sorológica, o que agrava ainda mais a cadeia de transmissão da infecção. Daí a importância do seguimento dos pacientes infectados. Sendo a infecção crônica pelo vírus da hepatite $B$, importante causa de morbidade e mortalidade no mundo e também uma das principais causas de descompensação hepática, cirrose e câncer de fígado, essa infecção crônica pode causar maior estresse e impactar de forma negativa na qualidade de vida do indivíduo, nas suas relações sociais e na realização de tarefas diárias, independentemente dos sintomas clínicos hepáticos, os quais estão relacionados com as manifestações extra-hepáticas e com as alterações cognitivas. Assim, as hepatites constituem um importante problema para os serviços de saúde, não apenas pela incidência elevada, mas especialmente pelo aumento da possibilidade de complicações das formas agudas, desenvolvimento de formas crônicas em longo prazo e as consequências que isso traz para os indivíduos infectados ${ }^{(15,19,20)}$.

Sugere-se o estudo de políticas públicas educativas para a abordagem desses indivíduos nos seus espaços de trabalho e nas suas respectivas famílias. Outra perspectiva que este trabalho vislumbra é a continuação de estudos sobre hepatite B, para aprofundamento de outras questões, considerando sua magnitude, formas de transmissão, distribuição e severidade.

\section{CONCLUSÃO}

O perfil do portador no presente estudo aponta para indivíduos do sexo masculino, heterossexual, casado, em idade produtiva e doador de sangue, cuja fonte de infecção não pôde ser estabelecida com precisão, apesar dos relatos de história anterior de procedimentos odontológicos e/ou cirúrgicos, sexualmente promíscuos e que tiveram hepatite viral no passado.

\section{REFERÊNCIAS}

1. Moreira T, Areias J. Hepatite B crônica. J Port Gastrenterol. 2009;16(5):187-91.

2. Secretaria de Saúde Pública do Rio Grande do Norte, Programa Estadual de DST e Hepatites Virais. Boletim Epidemiológico 2011 [acesso em 2014 Jan 02]. Disponível em: http://www.portal.rn.gov.br/ contentproducao/aplicacao/sesap/saude_destaque/ enviados/boletim_dst_aids_hv_2011_v4.pdf

3. Fonseca JCF. História natural da hepatite crônica B. Rev Soc Bras Med Trop. 2007;40(6):672-7.

4. Silva ACLG, Tozatti F, Welter AC, Miranda CC. Incidência e mortalidade por hepatite B, de 2001 a 2009: uma comparação entre o Brasil, Santa Catarina e Florianópolis. Cad Saúde Coletiva. 2013;21(1):34-9.

5. Cruz CRB, Shirassu MM, Martins WP. Comparação do perfil epidemiológico das hepatites B e C em um serviço público de São Paulo. Arq Gastroenterol. 2009;46(3):225-9

6. Ministério da Saúde (BR). Boletim epidemiológico: hepatites virais [periódico na internet]. 2012 [acesso em 2013 Jan 12];2(1). Disponível em: http://www.aids.gov. $\mathrm{br} / \mathrm{sites} / \mathrm{default} /$ files/anexos/publicacao/2012/51820/ boletim_epidemiol_gic_hepatites_virais_2012 ve_12026.pdf

7. Werneck G. Epidemiologia descritiva: qualidade das informações e pesquisa nos serviços de saúde. Epidemiol Serv Saúde. 2009;18(3):205-7.

8. Silva RSU, Ribeiro SAL, Silveira RP, Freitas MS. Avaliação da pré-triagem sorológica para o marcador do vírus da hepatite $\mathrm{B}$ (anti-HBc total) em candidatos à doação de sangue no Estado do Acre. Rev Soc Bras Med Trop. 2006;39(2):179-82.

9. Aquino JA, Pegado KA, Barros PL, Machado LFA. Soroprevalência de infecções por vírus da hepatite $\mathrm{B}$ e vírus da hepatite $\mathrm{C}$ em indivíduos do Estado do Pará. Rev Soc Bras Med Trop. 2008;41(4):334-77.

10. Ministério da Saúde (BR), Secretaria de Vigilância em Saúde, Departamento de DST, Aids e Hepatites Virais. ABCDE do diagnóstico para as hepatites virais. Brasília: Ministério da Saúde; 2009.

11. Martins AO, Viana AMA, Costa MS, Souza ADF. Perfil epidemiológico dos portadores crônicos de hepatite viral $\mathrm{B}$ atendidos em hospital do Distrito. Brasilia Med. 2008;45(4):264-71. 
12. Ministério da Saúde (BR), Secretaria de Vigilância em Saúde, Departamento de Vigilância Epidemiológica. Hepatites virais: o Brasil está atento. $3^{\mathrm{a}}$ ed. Brasília: Ministério da Saúde; 2008.

13. Ministério da Saúde (BR). Portaria $\mathrm{n}^{0} 3.318$, de 28 de outubro de 2010. Institui em todo território nacional, o Calendário Básico de Vacinação da Criança, o Calendário do Adolescente e o Calendário do Adulto e Idoso. Diário Oficial da União, Brasília, 29 Out 2010;(208):105.

14. Carlo FS, Lima JF, Sene M, Rosa NM, Cardoso VH, Aguiar JE. Perfil do portador de hepatite B do município de Maringá, Paraná, Brasil. Saúde Pesqui. 2008;1(3):241-6.

15. Teston EF, Silva RLDT, Marcon SS. Convivendo com hepatite: repercussões no cotidiano do indivíduo infectado. Rev Esc Enferm USP. 2013;47(4):860-8.

16. Instituto Brasileiro de Geografia e Estatística - IBGE. Estados: Rio Grande do Norte [acesso em 2014 Ago 2]. Disponível em: http://www.ibge.gov.br/estadosat/ perfil.php?sigla $=\mathrm{rn}$

17. Universidade Federal do Rio Grande do Norte, Hospital Universitário Onofre Lopes. Relatório epidemiológico do $3^{\circ}$ trimestre de 2012 [acesso em 2014 Ago 2]. Natal, 2012. Disponível em: http://www.huol.ufrn.br/doc/ relatorios/relatorio_epidemiologico2012.pdf
18. Osti C, Marcondes-Machado J. Vírus da hepatite B: avaliação da resposta sorológica à vacina em funcionários de limpeza de hospital-escola. Ciênc Saúde Coletiva. 2010;15(Supl 1):1343-8.

19. Ferrari CKB, Savazzi K, Honório-França AC, Ferrari GSL, França EL. Conhecimentos sobre hepatites virais numa amostra de estudantes brasileiros do Vale do Araguaia, Amazônia Legal. Acta Gastroenterol Latinoam. 2012;42(2):120-6.

20. Campolina AG, Dini PS, Ciconelli RM. Impacto da doença crônica na qualidade de vida de idosos da comunidade em São Paulo (SP, Brasil). Ciênc Saúde Coletiva. 2011;16(6):19-25.

\section{Endereço do primeiro autor:}

Erotides Maria Garcia Justino

Rua Antonio Nesi, 2127

Bairro: Morro Branco

CEP: 59056-210 - Natal - RN - Brasil

E-mail: erotides.2008@hotmail.com

\section{Endereço para correspondência:}

Iris do Céu Clara Costa

Avenida Salgado Filho, 1787

Bairro: Lagoa Nova

CEP: 59056-000 - Natal - RN - Brasil

E-mail: iris_odontoufrn@yahoo.com.br 